\title{
Factors influencing performance of public hospitals: The case of Vietnam
}

\author{
Duc Cuong Pham ${ }^{a^{*}}$ and Thi Sen Vu
}

${ }^{a}$ School of Accounting and Auditing, The National Economics University, Vietnam ${ }^{b}$ Faculty of Economics, Tay Bac University, Vietnam

\begin{tabular}{l}
\hline C H R O N I C L E \\
\hline Article history: \\
Received: March 18, 2019 \\
Received in revised format: April \\
92019 \\
Accepted: April 23, 2019 \\
Available online: \\
April 24, 2019 \\
\hline Keywords: \\
Performance \\
Public hospitals \\
Balanced scorecard \\
BSC
\end{tabular}
A B S T R A C T

\begin{abstract}
This paper presents an empirical investigation to identify the effects of different factors on the performance of North western public hospitals in Vietnam. Data were collected by using questionnaire delivered to 426 participants drawing from 42 public hospitals in the Northwest provinces of Vietnam. The study used correlation regression to determine the effects of different factors on the performance of the hospitals. The study used balanced score card method to study the effects of non-financial along with financial factors on the performance of the hospitals. The results show that financial figures were the most important factors influencing on the performance of the hospitals followed by customer, mission, internal process, training and staff development. Based on the research results, some key recommendations were proposed aiming to improve the performance of the public hospitals in Vietnam.
\end{abstract}

\section{Introduction}

The Northwest is a territory located in the West of the North of Vietnam, with four provinces, including: Hoa Binh, Son La, Dien Bien and Lai Chau. According to a report issued by the Northwest Steering Committee (2017), the Northwest is the region with the slowest economic development in the country. In fact, in 2017, the poverty rate in the Northwest region was the highest compared with other regions in the country with $31.24 \%$, while the Southeast region maintained the lowest poverty rate of $1.05 \%$ compared with the average of the whole country which was about $6 \%$. The Northwest has many natural conditions with hilly terrain, divided and unfavorable traffic. This is also one of the reasons leading to the slow development of transportation, education and health infrastructure in the region. In anthropology perspective, the Northwest region covers about 20 different ethnic groups and they require government to invest more money compared with other provinces or regions in Vietnam. According to the health sector summation report of the Northwest provinces in 2017, the quality of health services in the region has made significant progress compared with previous periods. There is an improvement in reproductive health care, a reduction in the rate of malnutrition in children, an increase in the ability to examine and treat more diseases, thus reducing the rate of patients, etc. However, the report also points out some * Corresponding author.

E-mail address: cuongpd@neu.edu.vn (D.C. Pham) 
limitations of public hospitals in the region where the quality of health services, limited in quantity and quality of human resources, the low level of financial autonomy, etc. On the other hand, synthesizing opinions of some treatment patients in some regional hospitals indicate that the quality of medical examination and treatment of public hospitals in the region has not met the expectations and in some cases, the hospital patients do not feel secure and wish to enjoy better quality of medical services. The patients also need to be transferred to advanced hospitals in big cities where in many cases hospitals do not accept health insurance. Therefore, it is necessary to study the factors affecting the performance of public hospitals in the region to improvements. Balance scorecard (BSC) (Kaplan \& Norton, 1992) investigates a firm according to four perspectives; namely internal processes, customers, learning and growth and financial figures. This paper provides an implementation of BSC method to determine possible factors for improvement of public hospitals in Vietnam.

\section{Literature Review}

According to $\mathrm{Vu}$ (2013), the performance in hospitals is based on the quality standards set by the World Health Organization. These standards include services provided, patients' health improvement and expectation, fairness in the provision of medical care, regardless of the payment methods and social contributions. According to Selina Ionete-Toplicianu et al. (2015), hospital performance reflects the quality of medical action and the ability to manage the available resources so that people receive appropriate health status, ensuring patient satisfaction. BSC is a tool developed by Kaplan and Norton (1992) as a means of assessing the performance of an organization based on not only traditional standards that is financial measure but also the non-financial measures to achieve the desire goals (Walker \& Dunn, 2006; Voelker et al. 2001; Peters et al., 2007). BSC measures the performance of a nonprofit organization primarily through data collection in terms of four perspectives; namely Customer; Internal process; Training and development of employees; and Finance. The following sections introduce each of these perspectives.

\section{Customers perspectives:}

Kaplan and Norton (2001) identified the methodology and organizational practices to satisfy the customers' requirements. Assessment information for customers will be applied to determine the performance measurements for the other perspectives of the BSC. In a not-for-profit organization, the customer perspective will be more important than other perspectives because customer satisfaction is a testament for the achievement of the mission of the organization (Niven, 2008, 2011; Poister \& Streib, 2005).

\section{Finance perspectives:}

Kaplan and Norton (2001) define the financial perspectives as a result of a sustainable budget growth target. In the nonprofit perspectives, the financial perspectives will check the performance of using cost whilst ensuring the benefits for customers. Niven (2008) also argues that the perspectives of finance in the nonprofit organization is indispensable because via this information the quality services will be collected with the existence of limited resources from the state budget and sponsors.

\section{Internal process perspective:}

Internal process perspective is used in the non-profit organizations instead of the Internal business process perspective which is applied in a business organization. Kaplan and Norton (2001) determine the methods and organizational practices merely used in the Internal process to fully realize the customers and stakeholders' expectations. Improving efficiency and achieving the organization's goals depend significantly on the improvement of the entity's Internal process.

\section{Training and development staff perspectives:}

This term is used in non-profit organizations to replace learning and development perspective in business organizations. This perspective defines the development and training process such as organizational practices and methods to promote innovation and organizational development (Kaplan \& Norton, 2001). Niven (2008) also documented that the success of one not-for-profit organizations and organization's mission depend on the skills and capabilities of the employees working for those entities. According to 
the contingency theory, the factors affecting the performance of the organization include internal and external factors (Mintzberg, 1979). Owen et al. (2001) also argued that the main factors that reduce the performance of the organization are shortage of understanding of the external environment, strategic vision, linkage between customers and internal processes.

For-profit organizations: There are many studies reporting the influence of BSC's perspectives on business performance in enterprises, in which the research of Sharabati and Fugaha (2014) has shown positive impact and strong influence of four perspectives: customer, internal business process, training and development, and finance on the business performance of Jordanian pharmaceutical companies. The impact of the above four perspectives on business performance in the study was $83.6 \%$, in which the perspectives of customer has the greatest impact on business performance of the enterprise. Zuriekat (2005) based on the study of random theory and the BSC method gave a research model showing the factors affecting the performance of the organization in terms of BSC including: Financial efficiency, customers, internal processes, innovation, employees, suppliers, environment, quality, community.

For the public sector and not-for-profit entities: According to Moullin (2002), a well-designed performance measuring system will ensure that the organizations provide high-quality, cost-performance services to meet the customers' needs. However, the performance measurement in the public services sector is complicated because it involves many stakeholders. This study has identified the necessary factors affecting the performance in the health sector such as clinical processes, patient satisfaction, cost control, human resource factors, etc. Having the same track of research Kaplan and Norton (2001), Niven (2003), Urrutia and Eriksen (2005), Owen et al. (2001), Yang et al. (2005) and Blackmon (2008) used quantitative research methods to test the performance of organizations through BSC method. Research results report independent variables including: Strategic planning, mission, customer, internal process, training and development staff, finance having a positive impact on the dependent variable. Specifically, the finance perspective had the largest influence on the performance of non-profit organizations.

Inheriting quantitative research methods and performance measuring indicators developed by Blackmon (2008) and Giffords and Dina (2003), Franklin (2011) examined the correlation between the strategic plan and performance based on 5 perspectives of BSC in non-profit organization. Research results indicate that the strategic plan and perspectives of BSC were closely correlated. Therefore, the impact of strengthening strategic planning activities will increase the impact on organizational performance. At the same time, enhancing the positive impact of BSC perspectives will promote positive performance of the non-profit organization.

Research conducted by Ghoneim and Baradei (2013) also identified various factors affecting the performance of the Egyptian nonprofit organization. These factors include strategic planning, mission, internal process, customers, finance which impact positively on the performance of the non-profit organization. The factors of training and development staff, volunteers did not have any significant on the performance of Egyptian non-profit organizations. Weerasooriya and Khatibi (2015) studied the impact of the factors on the performance of educational and non-governmental organizations in Sri Lanka, with four significant factors affecting the performance of organizations non-profit including strategic planning, internal process, customer, training and development staff. However, the financial and volunteers did not have any significance on the organization's performance. Thus, different studies have shown factors drawn from BSC affecting organizational performance. Inheriting the results of the above studies, the authors developed a research model as a basis for determining the factors affecting the performance of public hospitals in the Northwest region of Vietnam.

\section{Model and research hypothesis}

Based on the literature review of determinants affecting the performance in the method BSC indicated above, we design the research model as shown in Fig. 1.

Mission factor: This factor reflects the relationship between entity mission and decision making and implementing activities. It will be seen as the priority order to fulfill the mission in concurrence of vision, value strategy, and feasibility of strategy. 


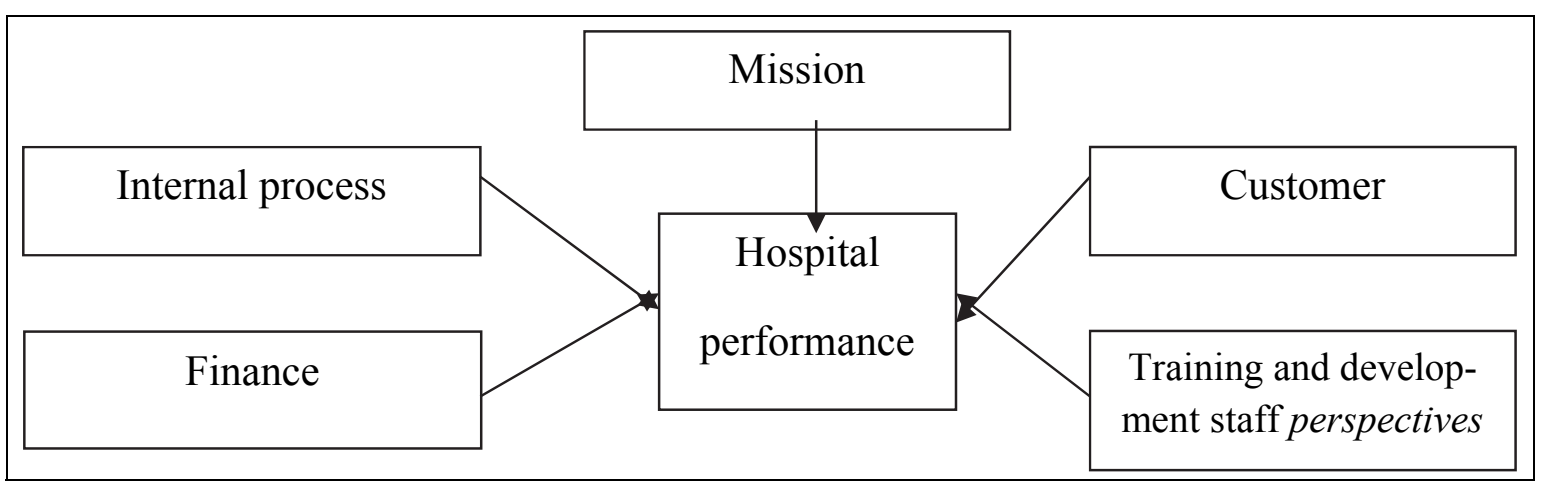

Fig. 1. Research model

Customer factor: Including indicators reflect customer satisfaction with the quantity and quality of service provided, meeting customers' requirements and expectations.

Internal process factor: Including indicators reflect the ability of organization to provide various services at good quality. This variable also includes the process and service activities provided according to quality standards declared.

Training and development staff factor: This includes indicators of measurement of working environment, employee satisfaction, employee's perception of work, the level of training to meet the requirements of work and skill level of staff.

Finance factor: This includes measuring indicators of revenues, expenditures and management of financial resources.

Hospital performance is dependent variable. It is measured by an indicator that evaluate the improvement and change of the unit on general synthetic indicators reflecting all perspectives of the organization's financial and non-financial activities.

Based on the research model, the author gives the following research hypotheses:

Hypothesis (H1): Mission factor has a positive effect on the Hospital performance;

Hypothesis (H2): Customer factor has a positive effect on the Hospital performance;

Hypothesis (H3): Internal process factor has a positive effect on Hospital performance;

Hypothesis (H4): Training and development staff factor has a positive effect on the Hospital performance;

Hypothesis (H5): Finance factor has a positive effect on the Hospital performance.

\section{Research methodology}

\subsection{Data collection}

Primary data is collected by both qualitative and quantitative approaches, more specifically:

Qualitative approach: It is based on the data obtained from in-depth interviews hospital director board and health departments; medical doctors who are the head of the departments, the vice of the departments, general accountants and chief accountants, those people who are working or being treated in public hospitals of the Northwest of Vietnam. The questions for interview are drawn from the literature review of previous studies. Interview questions are semi-structured aims to preliminarily remove items of inconsistent evaluation and to add appropriate new items affecting hospital performance. The results obtained from this step are used for constructing the survey questionnaires which will be used in the quantitative stage. 
Quantitative stage: The respondents of the survey questionnaires are managers, deans, assistant deans, deputy heads and board of directors of public hospitals in the Northwest region of Vietnam. The questionnaire includes: Part 1-General information about respondents which include age, gender, number of years of work, qualifications, positions, number of positions, hospitals, hospitals, provinces; Parts 2 to part 7 including questions using the Likert scale of 5 points from 1 is absolute disagree, 2 is disagree, 3 is neutral, 4 is agree and 5 is absolute agree. Part 2 includes questions asking about Mission; Part 3 questions asking about Internal procedures; Part 4 questions about customer perspectives; Part 5 questions about the perspectives of Training and development staff; Part 6 questions about Finance; Part 7 questions about the Hospital performance through assessing change, improving efficiency in hospitals. There were more than 500 questionnaires delivered and the number of valid questionnaires obtained from the extensive survey was 426. Duration of in-depth interviews and survey of the above questionnaires was carried out from March 2016 - June 2017.

\subsection{Data processing}

From 426 questionnaires collected we encoded them on SPSS 22 software and processed according to the following steps: First, we perform the verification of the scale's reliability. We have accepted the observed coefficients with Cronbach's Alpha greater than 0.7 and removed the observed variables with the correlation coefficient of less than 0.3 . The observed variables that ensure reliability were transferred to the Exploratory Factor Analysis (EFA) to extract the observed variables that were convergent and separated with the load factor greater than 0.5 and $\mathrm{KMO}$ having the value of greater than 0.5 and smaller than 1.0 while Bartlett test having Sig value of smaller than 0.05 and variance extract was more than $50 \%$. In addition, we performed regression analysis to assess the impact level of factors on the dependent variable which was associated with the performance of the hospitals. The regression analysis also helps to find the factor which has the highest impact on dependent variable either positively or negatively.

\section{Research results}

Table 1 demonstrates the results of the survey.

Table 1

Cronbach Alpha coefficients and load factors of variables in each factor

\begin{tabular}{|c|c|c|c|c|c|c|c|c|}
\hline \multirow{2}{*}{ Variables } & \multicolumn{5}{|c|}{ Component } & \multirow[t]{2}{*}{ Cronbach'Alpha } & \multirow[t]{2}{*}{ Number of items } & \multirow[t]{2}{*}{ Factor } \\
\hline & 1 & 2 & 3 & 4 & 5 & & & \\
\hline TC4 & .815 & & & & & \multirow{8}{*}{0.899} & \multirow{8}{*}{8} & \multirow{8}{*}{ Finance (TC) } \\
\hline TC6 & .766 & & & & & & & \\
\hline TC1 & .761 & & & & & & & \\
\hline TC5 & .754 & & & & & & & \\
\hline TC2 & .736 & & & & & & & \\
\hline TC3 & .697 & & & & & & & \\
\hline TC7 & .695 & & & & & & & \\
\hline TC8 & .601 & & & & & & & \\
\hline$\overline{\text { SM7 }}$ & & .824 & & & & \multirow{6}{*}{0.872} & \multirow{6}{*}{6} & \multirow{6}{*}{ Mission (SM) } \\
\hline SM8 & & .802 & & & & & & \\
\hline SM5 & & .764 & & & & & & \\
\hline SM4 & & .758 & & & & & & \\
\hline SM9 & & .740 & & & & & & \\
\hline SM6 & & .654 & & & & & & \\
\hline KH5 & & & .894 & & & \multirow{4}{*}{0.896} & \multirow{4}{*}{4} & \multirow{4}{*}{ Customer (KH) } \\
\hline KH4 & & & .859 & & & & & \\
\hline KH6 & & & .791 & & & & & \\
\hline $\mathrm{KH} 3$ & & & .740 & & & & & \\
\hline ĐT5 & & & & .805 & & \multirow{4}{*}{0.792} & \multirow{4}{*}{4} & \multirow{4}{*}{$\begin{array}{l}\text { Training and staff development } \\
\text { (DT\&PTNV) }\end{array}$} \\
\hline ĐT6 & & & & .727 & & & & \\
\hline ĐT7 & & & & .701 & & & & \\
\hline ĐT4 & & & & .668 & & & & \\
\hline QT2 & & & & & .795 & \multirow{4}{*}{0.734} & \multirow{4}{*}{4} & \multirow{4}{*}{ Internal Process (QTNB) } \\
\hline QT1 & & & & & .726 & & & \\
\hline QT3 & & & & & .709 & & & \\
\hline QT6 & & & & & .631 & & & \\
\hline
\end{tabular}


According to Table 1, loading factor in standard assurance factors is greater than 0.5 (from 0.601 to 0.894). At the same time, the authors tested the reliability of the scale in the above factors for the standard results of the Cronbach'Alpha coefficient $>0.7$ (from 0.734 to 0.899 ). Therefore, these 5 factors ensure the conditions for regression of the research model to assess the impact of each factor on the performance of public hospitals in the Northwest region of Vietnam.

\section{Table 2}

KMO and Bartlett's Test

Kaiser-Meyer-Olkin Measure of Sampling Adequacy. Bartlett's Test of Sphericity

Approx. Chi-Square

Sig.
5721.547

.000

According to Table $2, \mathrm{KMO}=0.891$, factor analysis is appropriate. With Bartlett testing having Sig value is 0.000 and Total Variance Explained is $64 \%$ much higher than $50 \%$ according to the standard, which proves that $64 \%$ of the data variation is explained by the above five factors. The results of the regression model obtained the results:

Table 3

Summary of the models

\begin{tabular}{cccccc}
\hline Model & $\mathrm{R}$ & R Square & Adjusted R Square & Std. Error & Durbin-Watson \\
\hline 1 & $.666^{\mathrm{a}}$ & .443 & .437 & .332 & 1.907 \\
\hline
\end{tabular}

a. Predictors: (Constant): Training and development staff, Mission, Internal process, Customer, Finance

b. Dependent Variable: Hospital performance

According to Table $3, \mathrm{R}^{2}=0.443$ which means that about $44 \%$ of the variation of the dependent variable is explained by 5 independent variables, including Mission; Customer; Internal process; Training and development staff; and Finance.

Table 4

ANOVA coefficient ${ }^{\mathrm{a}}$

\begin{tabular}{llccccc}
\hline Model & & Sum of Squares & df & Mean Square & F & Sig. \\
\hline 1 & Regression & 36.813 & 5 & 7.363 & 66.881 & $.000^{b}$ \\
& Residual & 46.235 & 420 & .110 & & \\
\cline { 2 - 7 } & Total & 83.048 & 425 & & & \\
\multicolumn{2}{l}{$\begin{array}{l}\text { a. Predictors: (Constant): Training and development staff, Mission, Internal process, Customer, Finance } \\
\text { b. Dependent Variable: Hospital performance }\end{array}$}
\end{tabular}

According to Table 4, F $=66.881$, Sig $=0.000<0.05$, thus rejecting the null hypothesis and conclude that there is a linear relationship between the dependent variable and the independent variable above. The results of the regression model of factors affecting the hospital performance are obtained in Table 5 as follows:

Table 5

Regression results in the research model

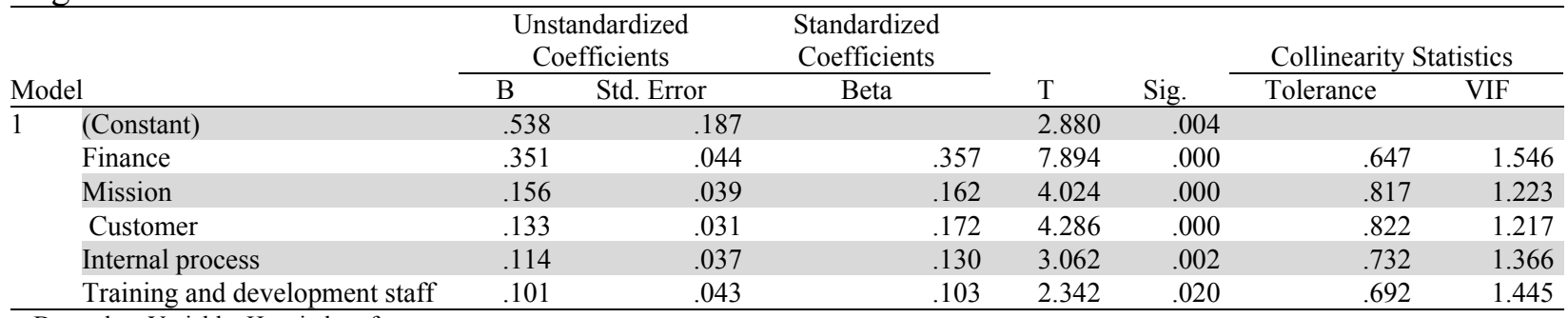

a. Dependent Variable: Hospital performance

Based on the results of Table 5, the dependent variable "Hospital performance" is defined as follows, Hospital performance $=0.538+0.357 \times \mathrm{TC}+0.162 \times \mathrm{SM}+0.130 \times \mathrm{QTNB}+0.172 \times \mathrm{KH}+0.103 \mathrm{DT} \& \mathrm{PTNV}$ VIP coefficient is less than 3 , so the regression equation has no multicollinearity between the independent variables and yields a desirable results for the regression model. 
In Table 5, the independent variables have coefficients $\beta$ of greater than zero and Sig value is smaller than 0.05 , so the factors: Finance, Mission, Customer, Internal process, Training and development staff, Finance have maintained positive effects on hospital performance when the level of significance is five percent. The positive influence of factors on Hospital performance is arranged in the following order of importance: Finance; Customer; Mission; Internal process; Training and development staff. In particular, the Financial factor has maintained a high coefficient of $\beta=0.357$ which is greater than the other factors, representing the greatest influence and plays an important role on the factors of public hospital performance in the region. The factor of Training and development has maintained the lowest impact among the factors with the coefficient of $\beta=0.103$. Table 6 shows the results of the survey.

Table 6

Summary of conclusions for research hypotheses

\begin{tabular}{|c|c|c|c|c|}
\hline $\begin{array}{l}\text { BSC } \\
\text { perspectives }\end{array}$ & $\begin{array}{l}\text { Influence } \\
\text { factor }\end{array}$ & $\begin{array}{c}\text { Coefficient } \\
\beta\end{array}$ & Sig & Conclude \\
\hline Mission & Mission & 0.162 & 0.000 & $\begin{array}{l}\text { The Mission factor has a positive effect on Hospital performance and } \\
\text { is statistically significant at } 95 \% \text {. Therefore, the hypothesis }\left(\mathrm{H}_{1}\right) \text { is ac- } \\
\text { cepted. }\end{array}$ \\
\hline Customer & Customer & 0.172 & 0.000 & $\begin{array}{l}\text { Customer factor has a positive effect on Hospital performance and is } \\
\text { statistically significant at } 95 \% \text {. Therefore, hypothesis }\left(\mathrm{H}_{2}\right) \text { is accepted. }\end{array}$ \\
\hline Internal process & $\begin{array}{l}\text { Internal } \\
\text { process }\end{array}$ & 0.130 & 0.002 & $\begin{array}{l}\text { Internal process factor has a positive effect on Hospital performance } \\
\text { and are statistically significant at } 95 \% \text {. Therefore, hypothesis }\left(\mathrm{H}_{3}\right) \text { is } \\
\text { accepted. }\end{array}$ \\
\hline $\begin{array}{l}\text { Training and } \\
\text { development staff }\end{array}$ & $\begin{array}{l}\text { Training and } \\
\text { development } \\
\text { staff }\end{array}$ & 0.103 & 0.020 & $\begin{array}{l}\text { Training and development staff factor have a positive effect on Hospi- } \\
\text { tal performance and are statistically significant at } 95 \% \text {. Therefore, hy- } \\
\text { pothesis }\left(\mathrm{H}_{4}\right) \text { is accepted. }\end{array}$ \\
\hline Finance & Finance & 0.357 & 0.000 & $\begin{array}{l}\text { Finance factor have a positive effect on Hospital performance and are } \\
\text { statistically significant at } 95 \% \text {. Therefore, the hypothesis }\left(\mathrm{H}_{5}\right) \text { is ac- } \\
\text { cepted. }\end{array}$ \\
\hline
\end{tabular}

\section{Discussion and recommendations}

According to our survey, all BSC perspectives, Mission, Customer, Internal process, Training and development staff, Finance, have maintained positive impacts on the performance of Northwestern public hospitals of Vietnam. The model has explained $44.3 \%$ of the changes on the hospital performance by independent variables in the regression equation. With the analysis results of the combined model and the results of interviews with hospital managers and related subjects, the authors discussed and proposed following instructive recommendations to improve the performance of the hospitals in the remote low income and inconvenient public hospitals of Vietnam. These public institutions are based on the priority order of each impact factor as follows:

\section{About Finance perspectives:}

The research results show that hypothesis $5\left(\mathrm{H}_{5}\right)$ is supported and there is a positive relationship between the Financial factor and the Hospital performance. Therefore, to strengthen financial position to promote the performance of hospitals in the region, first, hospital managers and managing agencies of the Vietnam Ministry of Health need to focus on improving the financial perspectives of the hospitals in the region:

First, there is a need to increase the annual hospital fee collection, ensuring a higher rate of hospital fee collection compared with the total amount of regular operating expenses in the hospital. This increase means that the hospital has to increase its financial autonomy as recently required by the Vietnamese government and the Ministry of Health. In order to increase the hospital fee collection, the hospitals must continuously improve the quality of medical services provided, increase the patient's satisfaction in order to increase the patients' attraction who believe in medical examination and treatment. Currently, hospital revenues include fees for patients with healthcare insurance (accounts for 92 percent) and fees from the ones who are covered by any healthcare program. The rate of participation in the healthcare is very high compared with the whole country, because most patients in the region are ethnic people, located in remote and disadvantaged areas which, under the government policies, are prioritized for health insurance and support from the state budget. However, when interviewing patients, there are many doubts about the 
quality treatments in the northwest hospitals. In addition, there are higher rate of concerns about the quality of services at the lower-level hospitals, for instance the district one. Moreover, nowadays there are improvements in transportation and economics, many patients choose to be treated at the higher-level hospitals located in the big cities, for example the hospitals in Hanoi capital. Currently, many people have financial ability to pay for high quality treatment services, which means the northwest hospitals lose potential sources of finance.

Second, according to the results of interviews with hospital managers, it is necessary to strengthen financial resources from the state budget to invest in facilities for clinics, treatment rooms, canteens and cafeterias in some district hospitals. These facilities would bring more comfortable conditions for patients and caregivers.

Third, according to the results of interviews with managers, the solution to increase hospital revenues can be executed by the socialization of external financial resources. Hospitals in the region should mobilize capital from organizations and individuals into constructions or developments of facilities, equipment, and good doctors in the field of voluntary medical examination and treatment. Having high service lead to reduction of patients moving to big-city hospitals which are always in over capacity situation. In addition, by providing high quality of health service the revenues for hospitals would be certainly higher. However, in order to attract socialized resources, it is necessary to study and build this project in a feasible way, ensuring success.

Fourth, within the revenue limits, the hospital needs to use cost effectively within the estimated budget to help the hospitals manage and control the financial circumstances every year. In order to use cost effectively, it is necessary to allocate operation cost for major drivers in hospitals such as administrative activities, purchasing activities, employee, professional activities, etc. in the hospitals. Moreover, according to the interview results, many health staff believe it is necessary to prioritize the allocation of salary costs, strengthen the regime for health officers in remote areas so that they have long-term commitment to work in remote areas like northwest region.

Fifth, under the autonomy mechanism in the public sector prescribed by the Vietnamese Government, on the roadmap to the year 2020, the public agencies such as hospitals will have to cover major cost of health services. It means that all regional hospitals will have to cover all direct expenses, wages and salaries, administration and wear and tear costs of fixed assets of the service provision. Therefore, in order to maintain and develop revenues at hospitals in the region, the quality of service need to satisfy the patients. Hospitals have to continue to attract patients and the examination and treatment at local hospitals is very important. Doing this well will have a multidimensional impact including the financial aspect to hospital performance. However, with the autonomy mechanism as above, many district hospitals leaders also believe that the Vietnamese government needs to reconsider autonomy, requires to consider the autonomy for remote hospitals, while medical equipment is still inadequate, the quality of health services is not attractive enough for those who are willing to pay at a high level, mainly attracting people with health insurance in the locality. Therefore, while some hospitals could be able to ensure partial financial autonomy, the others still need support from the state budget for regional hospitals to better perform their roles, functions and mission. In addition, for poor district hospitals in the Northwest region, the regime of prescribing health insurance fund and applying equal price ceilings among hospitals of the same class now leads to financial difficulties. Therefore, Vietnamese government needs more specific solution to support regional hospitals in this regard.

About Customers perspectives:

The customer is the second factor which has significant impact on the performance of public hospitals in the northwest region of Vietnam. The significant influence demonstrates the important role of customers on the hospitals' performance. This research result is consistent with the current practice, especially in the field of services where customer satisfaction is always the leading factor affecting the development of the unit. This factor is very typical for public hospitals in the Northwest. Therefore, to improve the performance of hospitals, it is necessary to focus on the following tasks: 
- Hospital should promote and enhance satisfaction from patients and their family members, including most ethnic minority people. For this group of customers, doctors and health officers should provide detailed instructions with the highest enthusiasm, good medicine, good treatments, etc.

- With specific regional limitations, improving hospital effectiveness will satisfy expectations from local patients and the local government, the ethnic communities in the region of Northwest, and the Vietnamese Ministry of Health. In order to accomplish this task, the hospitals itself should first provide quality services for patients, then the hospitals need to perform a specific task for mountainous areas. The local authorities and the Ministry of Health need to have separate policies in all aspects that contribute to good implementation of health care tasks for people in remote area.

About Mission perspectives:

This factor is the third most influential factor on the performance of the hospitals. To focus on increasing efficiency and effectiveness the public hospitals in the remote region of Vietnam should do the following tasks:

First, the hospitals need to determine the hospital's mission. After that the hospital managers should set tasks to be executed following the priority order.

Second, each hospital itself needs to set long-term strategy with the goal to achieve. It also needs to be aware of hospital mission, actions, and operation activities need to be followed.

Third, in order to achieve the hospital mission, it is necessary to be aware of the tasks for each individual and all staff in the hospital. This issue has been implemented in hospitals but not thorough and effective. Therefore, there is a need to increase awareness of each staff member in the hospital about the duties and responsibilities of the work associated with the hospitals' mission. It is necessary to attach the rights and the obligations in implementing tasks in a specific manner based on the mission of the hospital.

Fourth, for the Northwestern area, the hospitals' mission is to ensure equality and healthcare for people in ethnic minority and mountainous areas where many ethnic groups still have backward customs and practices. In healthcare, infrastructure conditions for access to health services are still difficult. In order to achieve this mission, the awareness of the roles and tasks of each staff member in the hospital plays an important role. In addition, the specific social policy regimes for "ethnic, highland, and disadvantaged areas" should continue to be promoted so that the hospitals in the region can achieve their mission.

About Internal process perspectives:

Research results show that hypothesis H3 is accepted, which means that the Internal process of hospitals has impact on hospital performance. This perspective includes (1) reducing the rate of patients transferred to higher-level hospital, (2) being able to treat diseases of public hospitals in mountainous areas, (3) short period of treatment and hospitalization, etc. However, to enhance the efficiency through improving the quality of medical services, hospitals should first improve the skills of the team of medical doctors, technicians, machinery and equipment to support treatment and medical supplies used in examination and treatment. This factor has great impact not only on the performance of public hospitals but also on the hospitals located in the northwest region of Vietnam. Therefore, hospital managers need to take into account the solutions relating to internal process to enhance hospital performance.

\section{About Training and development staff perspectives:}

Health care service is a special type of service, so the working efficiency of employees will have a great influence on the quality of service delivered and hospital performance. Therefore, focusing on solutions to improve the working efficiency of employees might be considered as the basic solution to improve the quality of medical services of public hospitals in the current region according to research results.

For public hospitals in the Northwest region of Vietnam, the hypothesis 4 is supported, which indicates that this factor has a positive effect on the performance of public hospitals in the region. The efficiency of service delivery will depend on the quality and performance of service providers, including staff, 
medical doctors and hospital service providers. Therefore, it is necessary to promote the quality of health work provided by employees. In order to improve the employee's efficiency, it is necessary to enhance the profession by training and the employees should also be managed by the results of work other than by the time.

\section{Conclusion and limitation of the paper}

In this paper, through qualitative research method and quantitative research method, we have performed a regression analysis to figure out the factors affecting the performance of the Northwestern public hospitals. The study has identified four factors with significant influence on the hospital performance. The results have provided some instructive suggestions for managers to improve the performance of public hospitals of the Northwest region of Vietnam. The study has shown not only financial factors but also non-financial factors may influence on the performance, statistically. Therefore, in order to improve the performance of public hospitals in the region, in addition to the solutions focusing on financial issues, it is necessary to focus on non-financial factors such as: Mission, customer, internal process, source hospital manpower, etc. The results of this survey are somewhat consistent with other results published in the literature (e.g. Inamdar et al., 2022; Gurd \& Gao, 2007; Grigoroudis et al., 2012; Wicks \& St Clair, 2007; Onwujekwe et al., 2010; Moule, 2006; Lee et al., 2007).

\section{Limitations of the study}

The study has pointed out factors that have an impact on the performance of Northwestern public hospitals, thereby helping hospital managers have appropriate solutions to improve the performance of the hospitals in the region. However, this study still has certain limitations such as the areas of data collection. We have not collected data from many mountainous areas of Vietnam- areas where healthcare conditions were low. The study finds $\mathrm{R}^{2}$ is less than $50 \%$, which means that the model merely explained only about $50 \%$ of factors affecting to the hospitals' performance. In addition, the research has not exploited the complex qualitative research method, so that some experts' opinions have not been collected for analysis.

\section{Acknowledgement}

The authors would like to thank the anonymous referees for constructive comments on earlier version of this paper.

\section{References}

Al-Shammari, H. A., \& Hussein, R. T. (2007). Strategic planning-firm performance linkage: empirical investigation from an emergent market perspective. Journal of Competitiveness Studies, 15(1/2), 15.

Blackmon, V. Y. (2008). Strategic planning and organizational performance: An investigation using the balanced scorecard in non-profit organizations. Capella University.

Government (2013). Decision No. 1064/QD-TTg on Approving the Master Plan on socio-economic development in the Northern Midlands and Mountainous Region to 2020, issued on July 8, 2013.

Government (2015). Decree No. 16/2015/ND-CP regulates autonomy for public non-business units, issued on February 14, 2015.

Franklin, P. W. (2011). Relationship between strategic planning and nonprofit organizational performance. Unpublished Ph. D. dissertation, Capella University: United States.

Ghoneim, N., \& Baradei, L. (2013). The impact of strategic planning on Egyptian non-profits' performance: an assessment using the balanced scorecard. Journal of US-China Public Administration, 10(1), 57-76.

Giffords, E. D., \& Dina, R. P. (2003). Strategic planning in nonprofit organizations: Continuous quality performance improvement-a case study. International Journal of Organization Theory \& Behavior, 7(1), 66-80. 
Grigoroudis, E., Orfanoudaki, E., \& Zopounidis, C. (2012). Strategic performance measurement in a healthcare organisation: A multiple criteria approach based on balanced scorecard. Omega, 40(1), 104-119.

Gurd, B., \& Gao, T. (2007). Lives in the balance: an analysis of the balanced scorecard (BSC) in healthcare organizations. International Journal of Productivity and Performance Management, 57(1), 6-21.

Inamdar, N., Kaplan, R. S., \& Reynolds, K. (2002). Applying the balanced scorecard in healthcare provider organizations/Practitioner's Response. Journal of Healthcare Management, 47(3), 179.

Ionete-Toplicianu, S., Toplicianu, V., \& Brezeanu, E. (2015). Performance in the public health systemis only a purely medical issue?. Procedia Economics and Finance, 20, 301-307.

Kaplan, R. S., \& Norton, D. P. (1992). The balanced scorecard: measures that drive performance.

Kaplan, R. S., \& Norton, D. P. (2001). Transforming the balanced scorecard from performance measurement to strategic management: Part I. Accounting horizons, 15(1), 87-104.

Lee, S. H., Ng, A. W., \& Zhang, K. (2007). The quest to improve Chinese healthcare: some fundamental issues. International Journal of Health Care Quality Assurance, 20(5), 416-428.

Mintzberg, H. (1979). An emerging strategy of "direct" research. Administrative science quarterly, 24(4), 582-589.

Moullin, M. (2002). Delivering Excellence in Health and Social Care. Open University Press.

Moule, P. (2006). E-learning for healthcare students: developing the communities of practice framework. Journal of advanced nursing, 54(3), 370-380.

Niven, P. R. (2011). Balanced scorecard: Step-by-step for government and nonprofit agencies. John Wiley \& Sons.

Niven, P. R. (2008), Balanced scorecard step-by-step for government and nonprofit agencies ( $2^{\text {nd }}$ ed).

Onwujekwe, O. E., Uzochukwu, B. S., Obikeze, E. N., Okoronkwo, I., Ochonma, O. G., Onoka, C. A., ... \& Okoli, C. (2010). Investigating determinants of out-of-pocket spending and strategies for coping with payments for healthcare in southeast Nigeria. BMC health services research, 10(1), 67.

Owen, K., Mundy, R., Guild, W., \& Guild, R. (2001). Creating and sustaining the high performance organization. Managing Service Quality: An International Journal, 11(1), 10-21.

Peters, D. H., Noor, A. A., Singh, L. P., Kakar, F. K., Hansen, P. M., \& Burnham, G. (2007). A balanced scorecard for health services in Afghanistan. Bulletin of the World Health Organization, 85, 146-151.

Poister, T. H., \& Streib, G. (2005). Elements of strategic planning and management in municipal government: Status after two decades. Public Administration Review, 65(1), 45-56.

Sharabati, A. A. A., \& Fuqaha, S. J. (2014). The Impact of Strategic Management on the Jordanian Pharmaceutical Manufacturing Organizations' Business Performance. International Review of Management and Business Research, 3(2), 668.

Urrutia, I., \& Eriksen, S. D. (2005). Application of the balanced scorecard in Spanish private health-care management. Measuring Business Excellence, 9(4), 16-26.

Voelker, K. E., Rakich, J. S., \& French, G. R. (2001). The balanced scorecard in healthcare organizations: a performance measurement and strategic planning methodology. Hospital Topics, 79(3), 13-24.

Vu, A. D. (2013), Measuring Quality of Health Care Services, Department of Quality Management, Ministry of health.

Walker, K. B., \& Dunn, L. M. (2006). Improving hospital performance and productivity with the balanced scorecard. Academy of Health Care Management Journal, 2, 85-110.

Weerasooriya, R. B., Khatibi, A. \& Alwis, A. D. (2014). The impact of strategic planning for training anhd educatinonal non government organizations Srilanka: An evaluation using the Balanced Scorecard. International Journal of Management Sciences and Business Research, 3(7), pp.48-62.

Wicks, A. M., \& St Clair, L. (2007). Competing values in healthcare: balancing the (un) balanced scorecard. Journal of Healthcare Management, 52(5).

Yang, C. C., Cheng, L. Y., \& Yang, C. W. (2005). A study of implementing Balanced Scorecard (BSC) in non-profit organizations: A case study of private hospital. Human Systems Management, 24(4), 285-300. 
Zuriekat, M. I. K. (2005). Performance measurement systems: An examination of the influence of the contextual factors and their impact on performance with a specific emphasis on the balanced scorecard approach (Doctoral dissertation, University of Huddersfield).

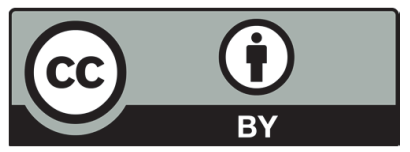

(C) 2019 by the authors; licensee Growing Science, Canada. This is an open access article distributed under the terms and conditions of the Creative Commons Attribution (CCBY) license (http://creativecommons.org/licenses/by/4.0/). 